\title{
A unidade financeirização e autorreprodução do capital: pressupostos marxianos e elementos contemporâneos
}

\author{
Rodrigo Fernandes Ribeiro ${ }^{1}$ \\ https://orcid.org/0000-0002-4912-988X \\ ${ }^{1}$ Universidade Federal de Ouro Preto, Instituto de Ciências Sociais Aplicadas, Departamento de Serviço Social, Mariana, MG, Brasil
}

\section{A unidade financeirização e autorreprodução do capital: pressupostos marxianos e elementos contemporâneos}

Resumo: Este artigo propõe-se analisar a unidade entre o processo de autorreprodução ampliada do capital e o fenômeno contemporâneo da financeirização. Na primeira parte são apresentados os fundamentados marxianos da teoria do valor-trabalho elaborada por Karl Marx nos três Livros de $O$ Capital, que identificou o processo de valorização do capital em suas formas simples, os ciclos da reprodução capitalista e os embriões do sistema de crédito. A partir desses pressupostos, são identificados os principais movimentos que a expansão da financeirização do capital proporcionou nos últimos anos, principalmente com o desenvolvimento do mercado de valores, a propulsão dos derivativos, a incidência sobre os países dependentes e, principalmente, a intensificação da concorrência capitalista e da exploração da força de trabalho. Em síntese, todo esse processo fortalece os processos produtivos e reprodutivos do capital, ao acelerar a rotação deste e expandir suas relações para todas as dimensões da vida social.

Palavras-chave: Financeirização. Autorreprodução do capital. Sistema de crédito. Exploração da força de trabalho.

The unity of capital financialization and self-reproduction: Marxian assumptions and modern elements Abstract: This study analyzes the unity observed between the process of expanded self-reproduction of capital and the modern phenomenon of financialization. The first part of the article presents Marx's foundations of the labor theory of value, as discussed in the three Volumes of Das Kapital. In this theory, Marx identified the process of capital valorization in its simple forms, the cycles of capitalist reproduction, and the first notions of the credit system. From these assumptions, this work identifies the main movements of the expansion of the financialization of capital in recent years, particularly with the development of the stock market, the promotion of the derivatives, the influence over dependent countries and, above all, the intensification of competition and exploitation of the labor force. This whole process strengthens the productive and reproductive processes of capital by accelerating its rotation and expanding its relations to all dimensions of social life.

Keywords: Financialization. Self-reproduction of capital. Credit system. Workforce exploitation.

Recebido em 15.02.2018. Aprovado em 25.05.2018. Revisado em 07.12.2018.

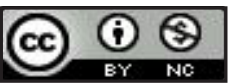

C O O(s) Autor(es). 2019 Acesso Aberto Esta obra está licenciada sob os termos da Licença Creative Commons Atribuição-NãoComercial 4.0 Internacional (https://creativecommons.org/licenses/by-nc/4.0/deed.pt_BR), que permite copiar, distribuir e reproduzir em qualquer meio, bem como adaptar, transformar e criar a partir deste material, desde que para fins não comerciais e que você forneça o devido crédito aos autores e a fonte, insira um link para a Licença Creative Commons e indique se mudanças foram feitas. 


\section{Introdução}

Muitos dos questionamentos sobre o capitalismo contemporâneo centram análise sobre o processo de financeirização do capital. Em maior ou menor dimensão, autores marxistas buscam levantar vários elementos sobre a profunda extensão da financeirização da vida sobre empresas não financeiras, os bancos e os indivíduos.

O objetivo central deste artigo está no desvelamento do papel que as finanças adquiriram sobre a produção de valor. A pretensa suplantação da produção de valor do capital industrial, ou mesmo uma dominação da esfera financeira sobre as forças produtivas de valor, perfazem parte dos equívocos que estão no entorno deste fenômeno. Para desmistificar esse complexo processo, a gênese e o desenvolvimento da produção e reprodução da vida são necessários para uma aproximação da concretude de tais problemas.

A teoria do valor-trabalho em Karl Marx consagrou-se na análise que melhor apresenta o movimento histórico em sua gênese e desenvolvimento do capital, assim como na apresentação dos fundamentos sociais e das leis tendenciais de desenvolvimento deste modo de produção e reprodução da vida. Este artigo parte na primeira seção dos elementos essenciais identificados por Marx na análise dos três livros de O Capital (2013, $2014,2017)$ que sintetizam o capital industrial produtor de mercadorias e de mais-valor, o capital de comércio de mercadorias e o capital de comércio de dinheiro, para, daí, na segunda seção, apresentar alguns elementos que perfazem a dinamização da esfera financeira dos últimos 40 anos.

\section{Pressupostos marxianos sobre a gênese e o desenvolvimento do sistema de crédito}

No Livro I de O Capital, Marx (2013) apresenta os fundamentos da produção simples de capital, partindo da mercadoria (M) como objeto que contém valor de uso e valor. O valor pelo qual a mercadoria é trocada é o tempo socialmente necessário para sua produção, sendo essa substância mediada pelo equivalente geral de uma mercadoria que se transforma socialmente nessa qualidade, o dinheiro (D).

Enquanto pilar do complexo social do capital, força expansiva que se reproduz e se revigora constantemente, está à produção do mais-valor. Trata-se do trabalho não pago - tempo excedente - que o capital explora da força de trabalho em uso. Pago por seu valor, a força de trabalho é uma mercadoria determinada pelo tempo necessário para a reprodução dessa mesma força de trabalho, ou seja, dos meios de subsistência necessários para sua reprodução. Esse tempo necessário - trabalho pago - é sempre acrescido do trabalho excedente não pago, que justifica o empreendimento do capitalista no processo de produção (MARX, 2013). Esse processo é mediado pela luta de classes, em que os capitalistas pressionam permanentemente por uma maior extração possível de trabalho não pago a força de trabalho em uso, e os trabalhadores, por outro lado, pressionam por uma maior fração do trabalho excedente não pago a fim de poder consumir mais meios de subsistência.

A fórmula universal do capital, D-M-D', expõe sinteticamente este processo. O capital constante (meios de produção e matérias-primas) é reposto integralmente no valor da mercadoria, enquanto o capital variável repõe o valor dos meios de subsistência necessários para o seu uso e, no processo de produção, produz o mais-valor com o alongamento ou a intensificação de seu uso. Portanto, a taxa de mais-valor é estabelecida na relação com o capital variável, único que pode produzir mais-valor, e a taxa de lucro é relacionada com o capital constante e variável.

Neste processo, a lei tendencial da queda da taxa geral de lucro é determinada pela necessária corrida concorrencial que busca baratear as mercadorias no sentido de potencializar a sua venda frente aos demais capitalistas. Neste sentido, com as inovações e descobertas tecnológicas, o capital constante é frequentemente acrescido, diminuindo o valor final da mercadoria e a própria taxa geral de lucro. Se, por um lado, essas inovações possibilitam uma maior taxa de mais-valor referente à exploração intensificada pelo maisvalor relativo, por outro, a massa de lucro expropriada por cada mercadoria é menor. Neste sentido, as leis contratendenciais, ou contra-arrestantes, como se refere Marx (2017) no Livro III de O Capital, são movimentadas no sentido de manter, ou mesmo aumentar, a taxa geral de lucro e, principalmente, a massa de lucro, a fim de impedir a queda da taxa. São medidas contra-arrestantes: o aumento do grau de exploração do trabalho, a compressão do salário abaixo do seu valor, o barateamento dos elementos do capital constante, a superpopulação relativa, o comércio exterior e o aumento do capital acionário (MARX, 2017). Os dois últimos estão intimamente ligados ao desenvolvimento do sistema de crédito no capitalismo desenvolvido.

Marx (2014) identifica no Livro II de O Capital a fórmula do ciclo da reprodução como D - M (FT+MP) - P - M' - D'. Esse movimento geral é representado pelos três ciclos do capital industrial: o ciclo do capital-dinheiro - D.... ' - , o ciclo do capital produtivo - P...P -, e do ciclo do capital-mercadoria $\mathrm{M}^{\prime}$ '...M ${ }^{1}$. Os distintos capitais cumprem, nesse processo, as condições necessárias para que o fundamento do processo de valorização se realize. 
No Livro III de $O$ Capital (MARX, 2017), o processo de reprodução global identifica a transformação do mais-valor em lucro, e a divisão consequente entre os diferentes capitais no processo. $\mathrm{O}$ capital comercial atua no sentido de garantir que o capitalista industrial privilegie a atividade, por demais complexa, de controlar e supervisionar o processo produtivo. A fórmula básica do capital comercial é D-M-D. Como momento essencial do processo de reprodução capitalista, o capital comercial cumpre a função de garantir a realização da mercadoria no consumo final, sendo que "[...] o lucro comercial é reduzido à alíquota do mais-valor total, que corresponde ao capital comercial como alíquota do capital total empregado no processo social da reprodução". (MARX, 2017, p. 329).

Visto somente no processo de circulação, o capital monetário equivale à representação fetichizada de D-D', em que tudo o que está no meio do processo oculta-se e dá a impressão de que é possível o dinheiro autonomizar-se e produzir dinheiro por si só. Esse capital de empréstimo tem o potencial de ser capital, de servir para o capitalista produtivo empreender e poder gerar mais-valor. Neste processo, o proprietário do capital pode alienar o seu valor para um terceiro, que consome o valor de uso capital e o valor na compra dos meios de produção e força de trabalho, tendo o prestamista recebido, depois de um prazo estabelecido, o mesmo valor emprestado acrescido do adicional dos juros (MARX, 2017).

$\mathrm{Na}$ totalidade desde processo de reprodução Marx identificou os diferentes agentes e a consequente divisão dos lucros entre o capitalista industrial, comercial e monetário - além do dono das terras (que não iremos tratar neste artigo).

O capital portador de juros é a forma mais elementar de capital de empréstimo de dinheiro, aquele que coloca o seu dinheiro - capital em potencial - a serviço do capital produtivo e requisita deste uma parte dos lucros. O valor destes juros é sempre indeterminado e depende, dentre outros fatores, da oferta e demanda destes recursos e do momento de crise ou depressão que faz com que o capital produtivo necessite de mais ou de menos capital para empreendê-lo na produção. Marx identifica esse potencial do capital-mercadoria ${ }^{2}$ disponibilizado por esse capitalista para outro capitalista do setor produtivo da seguinte forma:

Com base na produção capitalista, o dinheiro - aqui considerado expressão autônoma de uma soma de valor, sendo indiferente se esta existe, de fato, em dinheiro ou em mercadorias - pode ser convertido em capital e, mediante essa conversão, deixar de ser um valor dado para se transformar num valor que valoriza a si mesmo, incrementa a si mesmo. Ele produz lucro, isto é, permite ao capitalista extrair dos trabalhadores determinada quantidade de trabalho não pago, de mais-produto e de mais-valor, e de apropriar-se desse trabalho. Com isso, ele obtém, além do valor de uso que já possui como dinheiro, um valor de uso adicional, a saber, aquele de funcionar como capital. Seu valor de uso consiste aqui precisamente no lucro que ele produz ao se converter em capital. Nessa qualidade de capital possível, de meio para a produção do lucro, ele se torna mercadoria, mas uma mercadoria sui generis. Em outras palavras, o capital como tal torna-se mercadoria. (MARX, 2017, p. 385-386).

Em tal movimento, outro componente existente é o chamado capital fictício, visto por Marx no Livro III a partir da desenfreada especulação que se estabeleceu pelos negociantes de dinheiro, os setores bancários, e que em momentos de grande expansão capitalista desdobram as letras de câmbio comerciais e bancárias sem o devido lastro. Considerado por Marx (2017, p, 454) como o "outro lado do sistema de crédito", a centralização do capital monetário realizada pelos bancos contribui para a criação de diversas modalidades de capital de empréstimos, que vão desde as modalidades do crédito comercial, como os adiantamentos diretos com base no crédito pessoal, até os títulos públicos e ações de todos os tipos (MARX, 2017). Neste ínterim, os capitalistas prestamistas dividem-se entre os produtivos, que cedem crédito para atuar na reprodução, e os especulativos, que se preocupam exclusivamente em se apropriar dos lucros alheios:

O homem comum de negócios desconta suas letras para antecipar a forma-dinheiro de seu capital, mantendo, assim, em marcha o processo de reprodução; não para expandir o negócio ou obter capital extra, mas para compensar o crédito que dá por meio do crédito que recebe. [...] O especulador, no entanto, descontará suas letras especulativas para expandir seu negócio, para cobrir um negócio duvidoso com outro da mesma natureza, não a fim de obter um lucro, mas de obter a posse de capital alheio. (MARX, 2017, p. 482-483).

Mesmo ainda incipiente e centrado nas letras bancárias guarnecidas pelo Banco da Inglaterra - a autoridade monetária estatal dominante do século XIX - Marx já identifica os primeiros passos do mercado de valores enquanto um elemento ao mesmo tempo dinamizador e com potencial exclusivo que conduziria a reprodução capitalista desde então.

O sistema de crédito foi visto por Marx em sua nascente dinamização do processo como um todo, principalmente em sua função de centralização do capital ocioso e de potencial acelerador da rotação do 
capital. Estes dois momentos foram vistos no Livro II e III de $O$ Capital, interagindo com o processo como um todo em determinações recíprocas.

No livro II de $O$ Capital, o ciclo do capital total é composto pela mediação entre a esfera produtiva e a esfera da circulação. Para tanto, a seção II evidencia que o tempo de rotação do capital é a soma do tempo de produção e do tempo de circulação, incidindo diretamente sobre o valor e o preço da mercadoria. Com o prolongamento do tempo de circulação há uma diminuição na velocidade da rotação do capital, e com o encurtamento, há um aumento da velocidade. Marx identifica os progressos históricos que permitem a diminuição do tempo da circulação, que vão desde as comunicações e o transporte, até a facilitação destes para o consumidor final. Para ele "[...] o crédito, na medida em que possibilita, acelera e aumenta a concentração de capital numa só mão, contribui para abreviar o período de trabalho e, com ele, o tempo de rotação". (MARX, 2014, p. 361).

É no Livro III que Marx apresenta, mesmo que com grandes lacunas em seus manuscritos, as principais formulações sobre o sistema de crédito no processo global de reprodução. Marx elenca quatro pontos sobre o papel do crédito na produção capitalista - capítulo 27 -: o papel do sistema de crédito em compensar ou equalizar o movimento das taxas de lucro; a função de reduzir os custos da circulação ao acelerar a rotação dessa esfera; a criação das sociedades por ações, no que Marx chama de "transformação em empresas sociais"; e o poder quase que absoluto dos capitalistas que detém esse papel de dispor do capital e do trabalho social alheio (MARX, 2017, p. 493-498). Destas funções, Marx desdobra a tese de que o sistema de crédito tem o potencial de não só expandir as relações do capital sobre as diferentes dimensões da vida e constituir o mercado mundial, como de romper os limites e abrir as portas para um novo modo de produção ${ }^{3}$.

A base do sistema de crédito é o crédito comercial, que se trata "[...] do crédito que os capitalistas ocupados na reprodução concedem uns aos outros". (MARX, 2017, p. 536). Relacionado diretamente ao capital industrial, esse crédito é antecessor do crédito bancário, tendo as letras de câmbio enquanto principal produto. É uma extensão, uma garantia à realização da mercadoria que atua como capital-mercadoria e é utilizada tanto no consumo individual quanto no consumo produtivo:

Ao examinarmos esse crédito separadamente do crédito do banqueiro, fica claro que ele aumenta com o volume do próprio capital industrial. Capital de empréstimo e capital industrial são, aqui, idênticos. O capital emprestado é capital-mercadoria, que se destina ao consumo individual final, ou à reposição dos elementos constantes do capital produtivo. (MARX, 2017, p. 538).

O equilíbrio que se estabelece pelos empréstimos, pela emissão de títulos, pela venda destes no mercado bursáti $1^{4}$, nem sempre se relaciona de forma estável com o capital real. Como vimos, o capital fictício é uma categoria que se desenvolve com a especulação desenfreada das letras de câmbio que, ao desdobrarem-se em diversos empréstimos, podem não conectar-se com o lastro devido de capital. O descolamento desses créditos em momentos de crise de superprodução é pernicioso ao processo, fonte de erupções violentas:

[...] em épocas de crise e de paralisação dos negócios, o capital-mercadoria perde em grande parte sua capacidade de representar capital monetário potencial. O mesmo ocorre com o capital fictício, com os títulos portadores de juros, na medida em que circulam na Bolsa como capitais monetários. [...] A queda da cotação desses títulos nos boletins da Bolsa não tem nenhuma relação com o capital real que representam, mas sim com a solvência de seus proprietários. (MARX, 2017, p. 550).

É na instituição centralizadora da mercadoria capital que se concentra capital em poucas mãos e que se remetem títulos e créditos para os capitalistas produtivos. O poder dos bancos é o que garante o lucro adicional que estes puncionam do processo de reprodução como um todo. Visto como "a maior potência de capital", o Banco da Inglaterra encarnou esse poderio ao criar "[...] signos de valor que constituem para ele não apenas meios de circulação, mas também capital adicional, ainda que fictício, no valor nominal dessas cédulas não cobertas". (MARX, 2017, p. 601). É pelo "poder fabuloso" da centralização que essa "classe parasitária" tem o poder "[...] não só de dizimar periodicamente os capitalistas industriais, mas de intervir de maneira mais perigosa sobre a produção real, da qual esse bando não sabe absolutamente nada e com a qual não tem nenhuma relação". (MARX, 2017, p. 605). Marx aqui evidencia esse poder no âmbito do capital social total, na relação dentre capitais e, é claro, com a supervisão e controle do Estado burguês.

O grande potencial da formação do capital fictício é a capitalização, em que "[...] apaga-se até o último rastro toda a conexão com o processo real de valorização do capital e se reforça a concepção do capital como um autômato que se valoriza por si mesmo". (MARX, 2017, p. 524). Essa ilusão é estabelecida pelo capital acionário, os títulos da dívida pública - onde o título de propriedade dá o direito de participar proporcionalmente no mais-valor 
realizado -, e no capital bancário. As reservas que os bancos e demais instituições financeiras detém são abarrotadas destes títulos, denotando a profunda prevalência de capital fictício. Marx (2017, p. 527) vaticina que todo esse sistema de crédito tem o potencial ilusório de "duplicar e às vezes triplicar" o mesmo capital.

Contudo, não podemos cair na armadilha de afirmar que o comando soberano do dinheiro parasitário possa ser eternamente triunfante. É afirmada em Marx a prevalência do capital produtor de mais-valor no processo global de reprodução capitalista e que, em períodos de grande prosperidade, a demanda de capital de empréstimo possa, de fato, desdobrar esses capitais em algumas vezes, mas que, na apresentação da crise de superprodução, esses capitais fictícios esfumam-se nas primeiras horas do crash. É identificado nestes exemplos o potencial deste capital produtor de juros na expansão capitalista e na condução dos capitais produtivos, mas em nenhum momento podemos dizer que o trabalho vivo, produtor de mais-valor, acabou e o que comanda hoje é o trabalho morto informacional e fictício. Isso vale ainda mais no século XX e no alvorecer no século XXI.

\section{O processo de financeirização do capital na contemporaneidade}

O desenvolvimento do sistema financeiro é componente para entendimento da atual configuração da luta de classes e do processo de valorização do capital. O poderio das finanças passou a coordenar as rotas de investimento de capital, ampliando os seus mecanismos de punção de valor, extraído pela produção de forma cada vez mais intensa. Com o desenvolvimento moderno do mercado de consumo e de serviços, a financeirizaçãa $0^{5}$ passou a reger os fluxos de produção de mais-valor e a circulação de capital e de mercadorias.

A liberalização financeira que impactou todo o mundo desde a década de 1970, incrementando o poderio dos bancos e a apreensão sobre o conjunto da classe trabalhadora, requer a apresentação de algumas determinações que explicam esse processo. Antes da mais recente fase de mundialização do capital (CHESNAIS, 1996), em que se destaca esta nova expansão da financeirização capitalista, os mecanismos financeiros já tinham constituído intensa relação com as indústrias e os bancos em fins do século XIX e início do século XX. O chamado capital financeiro foi potencializado pelas fusões, pelos trusts, pela sociedade de ações e pela intensa expansão do mercado mundial, que promoveu a dominação imperialista sobre as nações dependentes e periféricas ${ }^{6}$.

A crise de 1929 estabeleceu os limites claros dessa modalidade de expansão capitalista sem precedentes em que as finanças pulverizaram o capital fictício em larga escala. Foi preciso a indução do Estado na regulação do mercado com incremento de investimentos para a expansão do mercado consumidor. Diante do perigo das primeiras experiências socialistas, os Estados burgueses necessitaram fazer concessões para os trabalhadores em luta, com a ampliação dos direitos sociais e acesso ao mercado consumidor que até então não tinham cedido. Além disso, o incremento deste mercado de consumo tornou-se outra via de valorização do capital. Sobre as finanças, os países de capitalismo avançado aplicaram algumas medidas de controle: sobre as taxas de juros, os preços e as quantidades de crédito; sobre as funções que as instituições financeiras poderiam desempenhar, como a separação das instituições de investimento e dos bancos; e, principalmente, garantindo o controle sobre os fluxos internacionais com a conversibilidade do dólar ao ouro e outros câmbios fixos (LAPAVITSAS, 2016).

Durante os anos de ouro do capitalismo - fim da Segunda Guerra Mundial até começo dos anos 1970 , a regulação das operações financeiras esteve ligada a políticas estatais indutoras da demanda nos países de capitalismo desenvolvido, assim como nos países dependentes. Essas vias de valorização foram essenciais para lucros estrondosos, crescimento econômico e taxas de produtividade crescentes. Nesse período, o consumo foi decisivamente ampliado para todas as classes sociais nos EUA, e na Europa toda uma rede de proteção social foi constituída sob a égide do bem-estar social. Todas essas medidas conviveram com taxas muito próximas do pleno emprego.

Foi somente na década de 1970 que os freios que regulamentavam o mundo das finanças foram soltos e uma nova onda expansiva do sistema de crédito empreendeu o processo de mundialização e financeirização do capital $^{7}$. A queda da taxa geral de lucro, impulsionada pelo excesso de capacidade dos países produtores de manufaturados e o aumento da composição orgânica do capital - mais trabalho morto, menos trabalho vivo , foram as principais determinações para que o endurecimento da ofensiva reacionária do capital empreendesse uma nova arquitetura financeira. Robert Brenner (2003, p. 58) identificou que a queda dos preços e, consequentemente, do lucro do setor dos manufaturados foi desastrosa, e que "[...] foi o declínio nas taxas de lucro desse setor por todas as economias capitalistas avançadas o principal responsável pela projeção da economia mundial de um longo boom num longo declínio entre 1965 e 1973”.

O beco sem saída do capital em seu projeto civilizatório abriu a crise estrutural do sistema sociometabólico do capital (MÉSZÁROS, 2002). A flexibilização do trabalho, a reestruturação produtiva, a refuncionalização do Estado, a obsolescência planejada das mercadorias, o incremento do complexo industrial-militar e outras medidas 
referentes à ofensiva reacionária do capital foram necessárias para reverter os obstáculos dos limites absolutos da autorreprodução ampliada e depressão contínua. Para tanto, a mundialização financeira do capital apresentouse enquanto parte da ofensiva contratendencial do capital em direção à retomada das taxas ampliadas de lucro.

As transformações tiveram como um dos focos centrais a política monetária, pois, com as dificuldades do processo de acumulação capitalista dos EUA, principalmente no que tange à crescente inflação e déficits comerciais, a quebra unilateral do acordo do sistema de Bretton Woods permitiu que os EUA mantivessem e elevassem sua hegemonia econômica. A relação direta do dólar ao ouro esvaneceu-se para que o dólar se autorreferenciasse e os EUA pudessem fortalecer seu poderio mundial e imperialista sobre todas as nações do mundo. Essa medida é considerada uma das principais portas de entrada do processo de financeirização em nível mundial, principalmente pela apreensão da dívida pública dos países dependentes que este processo intensificou em fins da década de $1970^{8}$.

Os anos 1980 e 1990 demarcam essa ofensiva radical que a literatura política e acadêmica nominou como neoliberal. Ataques aos sindicatos, precarização e flexibilização dos contratos de trabalho, foram as prescrições emitidas pelo chamado Consenso de Washington, assim como a contenção dos gastos públicos com as políticas sociais. A cartilha ainda indicava privatização das empresas nacionais, manutenção de reservas para o pagamento dos títulos da dívida pública e reorientação do projeto econômico ao destruir parques industriais e privilegiar setores primários e rentistas.

Esse contexto de reedição dos mecanismos de acumulação financeira nas décadas de 1970 e 1980 expõe o traço tendencial no processo de reprodução ampliada do capital nas crises financeiras. O montante excessivo da acumulação financeira sobre a produção futura constitui um ambiente liberalizado das amarras que buscam controlar esse capital-mercadoria. A euforia bursátil, que contagiou os capitais nos EUA nos anos 1990, é exemplo de todo um processo em que o capital fictício produzido pelos bancos só pode ser contido pelo mesmo mal, com a liquidez em mais capital fictício e a consequente intensificação da exploração da força de trabalho para a produção de mais-valor, e também o uso recorrente da dívida soberana dos países para conter esses problemas (CHESNAIS, 2010). Esse fetichismo do dinheiro é constantemente realimentado pelos mesmos mecanismos da acumulação financeira, gerando ainda mais crises:

A causa primordial dessas crises se encontra na diferença entre o montante, sempre mais elevado, dos créditos sobre a produção em curso e futura e a capacidade efetiva do capital engajado na produção os honrar, mesmo com a ajuda de políticas macroeconômicas dos Estados, mesmo com o crescimento sem cessar da taxa de exploração da força de trabalho. (CHESNAIS, 2010, p. 171).

David Harvey (2011) também analisa esses movimentos da relação entre produção e finança referente à crise capitalista de 2007. Retratando o pânico financeiro gerado pela inadimplência no pagamento das hipotecas subprime de alto risco, a quebra de instituições de investimento, bancos, empresas, e o salvamento estatal que não impediu os danos à economia, o autor retoma a gênese liberalizante das finanças e as medidas que vieram para sacrificar o trabalho. A irracionalidade de tal sistema se dá com os produtos e serviços financeiros criados que acabaram servindo como reativações e prolongamento de capitais fictícios fundamentais para circular capital excedente e impedir a desvalorização. A explosão fica evidente onde "o sistema de banco às escuras" (HARVEY, 2011, p. 26) se mostra alheio às possíveis consequências da financeirização em que até mesmo as empresas produtivas tornam-se jogadoras intensas. Como reitera Harvey $(2011$, p. 26),

Novos mercados estranhos surgiram, liderados pelo que se tornou conhecido como "sistema de banco às escuras", permitindo o investimento em trocas de crédito, derivativos de moeda e assim por diante. $\mathrm{O}$ mercado de futuros abarcou tudo desde o comércio de direitos de poluição até apostas sobre o tempo. [...] Os investidores puderam investir em derivativos de ativos e, finalmente, até mesmo em derivativos de contratos de seguros de derivativos de ativos.

Contudo, as crises financeiras, como a de 2007, se apresentam enquanto um momento fundamental da reprodução do capital, "[...] necessária para racionalizar as irracionalidades do capitalismo" e para levar a "[...] reconfigurações, novos modelos de desenvolvimento, novos campos de investimento e novas formas de poder de classe". (HARVEY, 2011, p. 18).

A relação auxiliar da financeirização com a exploração capitalista de mais-valor sobre a força de trabalho concretiza-se na intensificação do que Michel Husson (2010, p. 316) chama de "hiperconcorrência". A reprodução capitalista se estabelece em nova redistribuição do mais-valor a ser consumido ou acumulado pelos diversos canais, sejam eles financeiros ou produtivos. É na disputa pelas frações deste capital que se intensifica uma maior exploração sobre o conjunto da classe trabalhadora em que: 
[...] encontra-se a ideia que não é possível dissociar os fenômenos da exploração e da financeirização, os quais aparecem como duas componentes de uma mesma realidade. O capitalismo contemporâneo é antes de tudo um capitalismo superexplorador ("carniceiro", diria Aglietta): o aumento da taxa de exploração permite o restabelecimento da taxa de lucro sem engendrar novos espaços de acumulação na mesma proporção. $\mathrm{O}$ consumo da mais-valia permite então reduzir esta diferença. Nesse esquema de conjunto, a financeirização preenche uma dupla função: ela instaura uma concorrência exacerbada, necessária para manter um alto nível de pressão sobre a exploração; e estabelece um modo de repartição adequado às novas condições de reprodução do capital. (HUSSON, 2010, p. 333).

Portanto, a financeirização do capital tem como função preponderante a intensificação da exploração da força de trabalho, o retorno da rentabilidade e o aumento da taxa de lucros. Com o incremento da concorrência capitalista, os fluxos de investimento dinamizam a exploração, aprofundam a concorrência no valor da força de trabalho em uma dimensão mundial, mercantilizam a proteção social, além de constituírem sofisticados produtos e serviços financeiros que intervenham na punção sobre o mais-valor produzido pelo capital produtivo. Em síntese, "[...] a função principal da finança é abolir, na medida do possível, as delimitações dos espaços de valorização: ela contribui nesse sentido para a constituição de um mercado mundial”. (HUSSON, 2010, p. 318).

Outra questão fundamental para o entendimento da financeirização que o capital perpassa nos dias de hoje, trata da intervenção estatal. Não só o Estado empreende os chamados planos de austeridade para aprofundar a retirada de direitos sociais já conquistados pelos trabalhadores, como este tem dinamizado os instrumentos de títulos da dívida pública. Garantidor da solvência dos bancos e demais instituições financeiras, os bancos centrais tem servido ao guarnecimento público dos títulos privados. Costas Lapavitsas (2016, p. 249) identifica três traços de atuação do Estado como "canal de la acumulación financiarizada": com o controle sobre o dinheiro a partir do Banco Central; com o controle imperial sobre o dinheiro mundial, em uma forma de reverter tributos dos países em desenvolvimento para os desenvolvidos; e com a construção do terreno para que a financeirização frutifique, a partir da alteração dos marcos regulatórios e da supervisão das finanças (LAPAVITSAS, 2016).

Um dos feitos dos Estados e seus respectivos bancos centrais (a começar pelos EUA) foi implementar um controle global da inflação, que atingiu tanto os países desenvolvidos quanto os dependentes. Como a inflação é um risco para o capital de empréstimo, já que consome parte dos juros que elevam o preço das mercadorias, a tarefa das autoridades monetárias de todos os países em começo dos anos 1980 “[...] fue tratar de controlar la inflacion con sustanciales $y$ constantes aumentos del tipo de interés lo que abocó las economías a la recesion". (LAPAVITSAS, 2016, p. 251).

As diferentes modalidades de externalização da produção e reprodução do capital são fundamentais para a centralização e concentração de capital crescente. Dentre todos os movimentos contemporâneos da financeirização, a transnacionalização dos grandes grupos industriais tem empreendido processos de aquisições e fusões que avançam no sentido monopolista, mas que, ao mesmo tempo, compreende uma dominação destes grandes grupos sobre outros menores, sendo que permite maior liberdade para a decisão dos grupos financeiros, exigindo maior profundidade nos processos " $[. .$.$] de terceirizações, franchising, parcerias e acor$

Compreender que no ciclo do comércio de mercadorias ou de dinheiro se possa produzir valor escancara o fetiche do dinheiro que produz dinheiro, que equivale à mera aparência de um processo que requer a determinante produção de valor para que
possa existir. dos de cooperação entre estruturas empresariais no plano mundial”. (PAULANI, 2008, p. 126).

Uma das grandes transformações que se estabelecem nesse processo se dá, principalmente, na unidade indissolúvel que se estabelece nos grandes grupos financeiros, intervindo decisivamente na administração contábil das empresas não financeiras. Grandes fundos de investimento, fundos de pensão, e outras formas de concentração de capital detém o controle de tal riqueza, infligindo aos capitalistas que se apropriam de tal capital de empréstimo as diretrizes diversas de produtividade. A chamada governança corporativa é a chave dos preceitos que promovem transformações tais como reestruturações produtivas radicais, que geram desemprego em massa, e deslocalizações abruptas de plantas industriais para áreas em que a força de trabalho é mais barata.

De acordo com essas novas transformações gerenciais, a expansão da financeirização sobre as empresas não financeiras é uma das características dos últimos 40 anos. Essas empresas têm participado cada vez 
mais dos mercados financeiros abertos, no sentido de sair à frente na concorrência. A combinação das atividades é característica da financeirização, com implicações sobre os investimentos, os lucros, na organização interna das empresas não financeiras e na tendência à crise, sendo que no geral "[...] la financiarización representa, en cambio, la transformación de la combinación de las actividades financieras y no financieras, que integran la circulación de del capital productivo". (LAPAVITSAS, 2016, p. 279).

Na valorização bursátil que gerou a bolha da Nova Economia em fins do século XX, a compra e vendas de ações por empresas não-financeiras foi uma das principais determinações para que o estouro da bolha promovesse a quebra de muitas empresas produtivas do ramo da tecnologia. A hipertrofia na tomada de empréstimos foi gerada pelo fato de que as empresas não-financeiras pediam empréstimos não só para adiantar dinheiro injetado na produção, mas também para participar do jogo bursátil em busca de lucros financeiros. Robert Brenner (2003, p. 205) retrata esse processo:

Por meio de uma farra de empréstimos de proporções históricas, as empresas não-financeiras americanas estavam tornando-se as principais compradoras liquidas no mercado de ações americano, colhendo os benefícios da inédita revalorização de seus ativos que resultava e, não menos importante, sendo capazes de tomar mais empréstimos, adquirir mais ações e mais beneficiarem-se.

Contudo, por mais que haja disputa pela alíquota de mais-valor decorrente da indeterminada taxa de juros, os capitais concorrentes tendem a unificar-se, principalmente pela junção realizada pelos já mencionados grupos financeiros transnacionais. Leda Paulani (2008, p. 48) explica esse processo da junção dos ganhos produtivos com os monetários:

No plano dos capitais individuais, porém, particularmente quando se trata do grande capital internacionalizado que opera na arena mundial, combinar ganhos rentistas com ganhos produtivos é próprio da lógica de seu funcionamento, que é míope e não enxerga nenhum outro objetivo que não seja a expansão ampliada de seu ganho monetário. [...] As relações que ligam o grande capital produtivo e financeiro, de um lado, e o Estado na posição de emissor de capital fictício, de outro, mostram, no entanto, que esse incômodo não existe, a não ser para os microempresários, os donos de botequins e os proprietários de fabriquetas de fundo de quintal, condenados à "economia de mercado" e à geração de renda real.

Os países de capitalismo dependente também tiveram transformações gigantescas na expansão recente dos mecanismos financeiros. O processo de liberação financeira atingiu boa parte destes países, incluindo-se o Brasil, provocando mudanças nos sistemas financeiros locais, na expansão dos produtos e serviços financeiros, e principalmente na dependência do fundo público para os títulos da dívida e outras extrações realizadas pelo capital portador de juros. Costas Lapavitsas (2016, p. 313) identifica que a liberalização financeira provocou uma "financiarización subordinado", em que "[...] no se ha producido un retorno al imperialismo formal pero la financiarización en los paises en vías de desarrollo ha tenido un carácter subordinado que se deriva de la naturaleza jerárquica y explotadora de las interacciones en el mercado mundial'. Tais mudanças são datadas principalmente do fim dos anos 1990, sendo que a interação com o sistema financeiro internacional se dá, principalmente, pelo domínio da moeda mundial - o dólar - e o estabelecimento dos bancos estrangeiros (LAPAVITSAS, 2016).

Em síntese, esses países dependentes foram transformados em "plataformas de valorização financeira internacional" (PAULANI, 2008, p. 35), elevando o padrão de dependência e exigindo destes países cada vez mais punção de valor de seus processos produtivos ou do fundo público a fim de satisfazer a ânsia por lucros destes setores ${ }^{9}$.

\section{Considerações Finais}

Os elementos reunidos neste artigo demonstram a profunda articulação entre o fenômeno da financeirização e o processo de autorreprodução ampliada do capital. O mundo das mercadorias não só expandiu para diversos setores da vida social, como aprofundam a concorrência intercapitalista e o processo de exploração da força de trabalho.

É na esfera da circulação de mercadorias que os distintos capitais interagem e empreendem o processo de reprodução. O ciclo do capital-mercadoria e o ciclo do capital-dinheiro são fundamentais para que o determinante capital produtivo de mais-valor possa realizar-se. Compreender que no ciclo do comércio de mercadorias ou de dinheiro se possa produzir valor escancara o fetiche do dinheiro que produz dinheiro, que equivale à mera aparência de um processo que requer a determinante produção de valor para que possa existir. 
Portanto, ao invés de suplantar a produção de valor que o capital industrial empreende na vida social deste modo de produção, a financeirização possibilita uma maior aceleração da rotação do capital e uma dinamização da vida sob as finanças que faz com que o poderio das instituições financeiras esteja na possibilidade de conduzir o excedente de capital para plantas industriais diversas em qualquer parte do mundo e pressionar violentamente o rebaixamento do valor da força de trabalho para a apreensão de uma maior exploração destas. A externalização ao processo produtivo e a imbricação entre capitais perfazem as atuais configurações deste processo.

\section{Referências}

BRENNER, R. O boom e a bolha: os Estados Unidos na economia mundial. Rio de Janeiro: Record, 2003.

CHESNAIS, F. A mundialização do capital. São Paulo: Xamã, 1996.

CHESNAIS, F. A proeminência da finança no seio do "capital geral”, o capital fíctício e o movimento contemporâneo de mundialização do capital. In: BRUNHOFF, S. de et al. A finança capitalista. São Paulo: Alameda, 2010. p. 95-182.

HARVEY, D. O enigma do capital e as crises do capitalismo. São Paulo: Boitempo, 2011.

HILFERDING, R. O capital financeiro. São Paulo: Nova Cultural, 1985.

HUSSON, M. Finança, hiperconcorrência e reprodução do capital. In: BRUNHOFF, S. de et al. A finança capitalista. São Paulo: Alameda, 2010. p. 301-336.

LAPAVITSAS, C. Beneficios sin producción: como nos explotan las finanzas. Madrid: Traficantes de sueños, 2016.

LENIN, V. I. Imperialismo, estágio superior do capitalismo: ensaio popular. São Paulo: Expressão Popular, 2012.

MARX, K. O capital: crítica da economia política: Livro I: o processo de produção do capital. São Paulo: Boitempo, 2013.

MARX, K. O capital: crítica da economia política: Livro II: o processo de circulação do capital. São Paulo: Boitempo, 2014.

MARX, K. O capital: crítica da economia política: Livro III: o processo global da produção capitalista. São Paulo: Boitempo, 2017.

MÉSZÁROS, I. Para além do capital: rumo a uma teoria da transição. São Paulo: Boitempo, 2002.

PAULANI, L. Brasil delivery: servidão financeira e estado de emergência econômico. São Paulo: Boitempo, 2008.

\section{Notas}

1 Processo analisado principalmente nos quatro primeiros capítulos do Livro II de O Capital (MARX, 2014).

2 "A forma de empréstimo que, em vez da forma da venda, é característica dessa mercadoria - do capital como mercadoria-e que, além disso, ocorre também em outras transações resulta já da determinação de que o capital aparece aqui como uma mercadoria, de que o dinheiro, como capital, converte-se em mercadoria." (MARX, 2017, p. 388).

3 “Tais são as duas características intrínsecas ao sistema de crédito: por um lado, ele desenvolve a mola propulsora da produção capitalista, o enriquecimento mediante a exploração do trabalho alheio, até convertê-los no mais puro e colossal sistema de jogo e fraude e limitar cada vez mais o número dos poucos indivíduos que exploram a riqueza social; por outro lado, estabelece a forma de transição para um novo modo de produção." (MARX, 2017, p. 499-500).

4 Referente às negociações de títulos e ações na Bolsa de Valores.

5 A síntese do economista grego Costas Lapavitsas aponta o que seria a essência do processo de financeirização. Para ele "[...] la financiarización es una tranformanción sistémica de las economias capitalistas avanzadas que se articula em torno de los câmbios de conducta subyacentes a las empresas no financieras, los bancos e los hogares". (LAPAVITSAS, 2016, p. 37). Este artigo não analisará, por falta de espaço, a expansão de produtos e serviços financeiros ao dispor dos indivíduos e de um contingente cada vez maior da classe trabalhadora, que proporciona, segundo Lapavitsas (2016), o processo de expropriação financeira sobre a renda dos salários destes indivíduos.

6 Aqui tanto Rudolf Hilferding (1985) e Vladimir Lenin (2012) formularam contribuições fundamentais para a análise deste período histórico de grande expansão capitalista.

7 O poderio da dominação da finança foi interrompido momentaneamente após a crise de 1929, em que uma massa importante de capital fictício foi desvalorizada. A“[...] retomada de uma acumulação de dinheiro 'ocioso', frente uma acumulação real efetuada na produção real [...]" só foi possível com a emergência da crise estrutural do capital na década de 1970 (CHESNAIS, 2010, p. 149). Costas Lapavitsas (2016) identifica várias similaridades entre a expansão financeira do inicio do século XX e a retomada a partir da década de 1970, principalmente com a interpenetração entre o âmbito das finanças e a esfera da produção. No entanto, o economista identifica que "[...] hay diferencias significativas entre los dos períodos. La financiariazación no ha dado lugar a zonas de comercio exclusivas asociadas con imperios territoriales y los bancos no dominan el panorama por encima de las empresas no financieras". (LAPAVITSAS, 2013, p. 70).

8 Leda Paulani (2008, p. 111) qualificou essa "nova fase” coma seguinte afirmação: "Esta é marcada pela exacerbação da valorização financeira, pela retomada da força do dólar norte-americano como meio internacional de pagamento, pela intensificação, em escala ainda não vista, do processo de centralização de capitais e pela eclosão da terceira revolução industrial, com o surgimento da chamada "nova economia"'.

9 Leda Paulani (2008, p. 91) chama essa relação subordinada de "servidão financeira". Em síntese ela afirma: "Nos países ditos emergentes, transformados em plataformas de valorização financeira internacional, o Estado não só produz volumes substantivos desse 'capital caído do céu', 
para usar os termos de Marx, como garante, pela imposição de metas elevadíssimas de superávit primário, a extração de renda real necessária para 'honrar' o serviço desse capital fictício, cujo preço ele mesmo fixa. A arquitetura financeira internacional, baseada numa moeda puramente fiduciária, sanciona mundo afora a valorização fictícia desses capitais fictícios, aumentando a pressão sobre os Estados nacionais periféricos para que funcionem como aspiradores de renda real ainda mais violentos". (PAULANI, 2008, p. 64-65).

\section{Rodrigo Fernandes Ribeiro}

roferrib@yahoo.com.br

Doutorado em Serviço Social pela Universidade Federal de Santa Catarina (UFSC)

Professor do Departamento de Serviço Social da Universidade Federal de Ouro Preto (UFOP)

\section{UFOP}

Instituto de Ciências Sociais Aplicadas

Rua do Catete, 166 - Centro

Mariana - Minas Gerais - Brasil

CEP: $35.420-000$

\section{Agência financiadora \\ Não se aplica.}

\section{Contribuições dos autores}

Não se aplica.

\section{Consentimento para publicação}

Não se aplica.

\section{Conflito de interesses}

Não há conflito de interesses.

Aprovação por Comitê de Ética e consentimento para parti-

cipação

Não se aplica. 